\title{
INCREASE IN QTC DISPERSION PREDICTS ARRHYTHMIC EVENTS IN PATIENTS WITH CARDIAC RESYNCHRONIZATION THERAPY
}

\author{
Cuneyt Kocas, Okay Abaci, Kadriye Orta Kilickesmez, Ferid Aliyev, Yusuf Atayev, Cengizhan Turkoglu, Cengiz Celiker
}

Aim. Benefits of CRT on mortality and morbidity in patients with severe CHF are clear but the effect of CRT on sudden cardiac death is more controversial. It has been suggested that CRT may catalyze arrhythmogenicity by reversing the normal depolarization pattern. The purpose of this study was to examine the effect of CRT on dispersion of repolarization as assessed by ECG. We also sought to determine the value of dispersion of repolarization ECG parameters in predicting the occurrence of major arrhythmic events (MAE) in follow-up.

Material and methods. A total of 48 patients with end-stage heart failure and QRS duration >120 ms underwent CRT. QT dispersion (QTd), T peak t end interval (Tpe) and $T$ peak t end dispersion (Tpe dispersion) were measured before and immediately after CRT implantation. All patients were followed at least 12 months for ventricular tachycardia or fibrillation that were treated with antitachicardia pace or cardioversion. Results. Over $16 \pm 7.1$ months, 14 patients had a MAE. Compared to baseline, after CRT, QTC dispersion (84.66 \pm 37.7 vs $100.36 \pm 47.4, p=0.04)$ and Tpe interval (104.1 \pm 20.4 vs $122.03 \pm 33, p=0.02)$ increased significantly. Increase in QTD ( $\Delta Q T D)$ (31.66 \pm 39.5 vs $5.57 \pm 5.59, \mathrm{p}=0.03$ ), and QTC dispersion ( $\Delta \mathrm{QTC}$ dispersion) $(40.19 \pm 46.6$ vs $4.39 \pm 14.35, p=0.04)$ from baseline was signifcantly higher in MAE group. In multiple regression analyses, $\triangle Q T c$ dispersion predicted MAE $(p=0.045$, Cl: $1.000-1.033)$
Conclusion. Immediately after CRT implantation QTC dispersion and Tpe interval increases and increase in QTc dispersion predicts MAE in one year follow up.

Russ J Cardiol 2014, 4 (108), Engl.: 10-14

Key words: CRT, repolarization dispersion, major arrhythmic events, QT dispersion. Department of Cardiology, Istanbul University Institute of Cardiology, Istanbul, Turkey.

Corresponding author. Cuneyt Kocas, MD, Istanbul University Institute of Cardiology, Department of Cardiology, Cardiologist, Instructor; Haseki, Aksaray 34350, Istanbul/Turkey, Tel: +905059383527, Fax: +902164693796, e-mail: cuneytkocas@hotmail.com

Received May 12, 2013.

Revision received May 22, 2013.

Accepted May 29, 2013.

\section{УВЕЛИЧЕНИЕ ДИСПЕРСИИ QТС ПРОГНОЗИРУЕТ АРИТМИЧЕСКИЕ СОБЫТИЯ У БОЛЬНЫХ С СЕРДЕЧНОЙ РЕСИНХРОНИЗИРУЮЩЕЙ ТЕРАПИЕЙ}

\author{
Cuneyt Kocas, Okay Abaci, Kadriye Orta Kilickesmez, Ferid Aliyev, Yusuf Atayev, Cengizhan Turkoglu, Cengiz Celiker
}

Цель. Преимущества сердечной ресинхронизирующей терапии (CRT) в снижении смертности и заболеваемости больных с тяжелой XСН ясны, но действие CRT при внезапной сердечной смерти является более спорным. Было высказано предположение, что CRT может катализировать аритмогенность, реверсируя нормальную деполяризационную структуру. Целью данного исследования было изучить влияние CRT на дисперсию реполяризации, при оценке ЭКГ. Мы также стремились определить значение дисперсии реполяризации параметров ЭКГ в прогнозировании возникновения крупных аритмических событий (МАЕ) в последующем.

Материал и методы. Всего 48 пациентов с терминальной стадией сердечной недостаточности и длительностью комплекса QRS >120 мс прошли CRT. Дисперсия QT (QTd), Т пик t end интервал (Tpe) и Т пик t end дисперсии (Tpe дисперсии) были измерены до и сразу после CRT имплантации. Все пациенты находились под наблюдением, по крайней мере, 12 месяцев, желудочковая тахикардия или аритмия лечились кардиостимуляцией или кардиоверсией.

\section{Introduction}

Cardiac resynchronization therapy (CRT) has become an established adjunctive treatment to optimal pharmacologic therapy in patients with advanced chronic heart failure (CHF), diminished left ventricular (LV) function and cardiac dyssynchrony [1]. Several studies have demonstrated that CRT improves ventricular haemodynamics, quality-of-life, exercise capacity, and reduces mortality and hospitalization rates in patients with advanced CHF [2-4]. Despite clear benefits of CRT on mortality and morbidity in patients with severe CHF, the effect of CRT on sudden cardiac death is more controversial. In the Comparison of Medical Therapy, Pacing and Defibrillation in Heart Failure
Результаты. Более 16 \pm 7.1 месяцев у 14 пациентов были MAE. По сравнению с исходными данными, после CRT, QTс дисперсия (84.66 \pm на 37,7 против $100.36 \pm 47.4, p=0,04)$ и Тре интервал $(104.1 \pm 20.4$ против 122.03 $\pm 33, p=0.02)$ значительно увеличились. Увеличение QTD (t QTd) (31.66 \pm 39.5 против

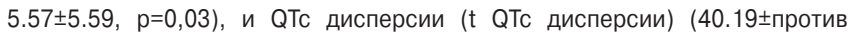
46.64.39 $\pm 14.35, p=0,04$ ) от исходного уровня были значительно выше в группе c MAE. При множественном регрессионном анализе $\triangle Q T c$ дисперсия предсказывала развитие MAE ( $\mathrm{p}=0,045$ (Cl): 1.000-1.033).

Заключение. Сразу после CRT имплантации QTc дисперсии и Тре интервал увеличиваются, и увеличение QTс дисперсии прогнозирует MAE при наблюдении в течение одного года.

Российский кардиологический журнал 2014, 4 (108), Англ.: 10-14

Ключевые слова: CRT, дисперсия реполяризации, крупные аритмические события, дисперсии QT.

(COMPANION) trial, the addition of an implantable cardioverter-defibrillator (ICD) to CRT was necessary to reduce global mortality and sudden cardiac death $[5,6]$. There have been several case reports over the past 5 years describing significant ventricular proarrhythmia, which manifests primarily as ventricular tachycardia (VT) storm. It has been suggested that CRT may catalyze arrhythmogenicity by reversing the normal depolarization pattern from endocardium to epicardium, which enhances transmural dispersion of repolarization and propagation of early after-repolarizations. These changes may facilitate the development of ventricular tachyarrhythmias [7]. In this light the purpose of this study was to examine the effect of 
CRT on dispersion of repolarization as assessed by ECG in a population of HF patients who received CRTICDs. We also sought to determine the value of dispersion of repolarization electrocardiogram (ECG) parameters in predicting the occurrence of ventricular arrhythmias in follow-up.

\section{Material and methods}

Patients. The study population consisted of 48 consecutive patients who had undergone successful CRD-D placement at our clinic between February 2008 and August 2010. The study protocol was approved by the local ethics commitee. All patients gave written informed consent, and the study was approved by the local ethics committee.

The inclusion criteria for our study were as follows: 1New York Heart Association (NYHA) functional class III or IV HF symptoms despite optimal medical therapy. 2Left ventricular ejection fraction $<35 \%$ as assessed by echocardiography, angiography, or radionuclide scanning. 3QRS duration $>130 \mathrm{~ms}$ or QRS $<130 \mathrm{~ms}$ and left intraventricular dyssynchrony as assessed by transthoracic echocardiography with Doppler tissue imaging analysis (difference of at least $60 \mathrm{~ms}$ between the timing of the peak systolic velocities of the septum versus the lateral wall. Exclusions criteria were: 1- contraindications to cardiac pacing; 2- myocardial infarction or acute coronary syndrome within the previous 3 months; 3-presence of comorbidities likely to threaten survival for 12 months.

Implantation technique. The CRT device with a biventricular pacemaker (C174AWK, Medtronic, Minneapolis, MN, USA) was implanted according to the established methods reported previously. Transvenous left ventricular pacing was performed in all cases. Under the guidance of coronary sinus angiograms, left ventricular lead was introduced into the lateral or posterolateral cardiac vein. The right ventricular lead was implanted in the apex. The final position was determined visually with the right and left anterior oblique views.

ECG parameters. ECG was recorded before and within 24 hours postimplantation. Twelve-lead body surface electrocardiograms were recorded at a speed of $50 \mathrm{~mm} / \mathrm{s}$. Two different experts, who were blinded to follow-up of the patients, manually analyzed all ECGs. For each ECG, the following parameters were measured: heart rate, QRS duration, QT interval, QT dispersion, Tpeak-Tend ( $\mathrm{Tp}-\mathrm{e})$, and $\mathrm{Tp}-\mathrm{e}$ dispersion. For each parameter, the difference between postimplantation and baseline values ( $\Delta \mathrm{QRS}),(\Delta \mathrm{QT} \mathrm{T}),(\Delta \mathrm{QT}$ dispersion $),(\Delta \mathrm{Tp}-\mathrm{e})$, and $(\Delta \mathrm{Tp}-\mathrm{e}$ dispersion) was calculated. Each measurement represented the average of the 12 leads. QTc was calculated using the Bazett Formula. QT interval was measured from the beginning of the QRS complex to the end of T wave, defined as the tangent to the downslope of the $\mathrm{T}$ wave and the isoelectric line.22 QT dispersion was defined as the difference between the maximum and the minimum QT interval of the 12 ECG leads. $\mathrm{Tp}-\mathrm{e}$ was measured in all derivations and was obtained from the difference between QT interval and QT peak interval (measured from the beginning of the QRS to the peak of the T wave). In the case of negative or biphasic T waves, QT peak was measured to the nadir of the $\mathrm{T}$ wave. $\mathrm{Tp}-\mathrm{e}$ dispersion was obtained by the difference between the maximum and the minimum Tp-e interval in the precordial leads. Pearson correlation coefficient (r) between the two observers for QRS, QT, $\mathrm{Tp}-\mathrm{e}$ was $0.93,0.79$ and 0.85 respectively. This coefficient evaluating intraobserver variability for QRS, QT and $\mathrm{Tp}-\mathrm{e}$ was $0.95,0.81$ and 0.88 , respectively.

Arrhythmic events-follow up. Patients were evaluated 1 month after implantation and every 3 months thereafter for 1 year. Occurrences of ICD shocks or antitachycardia pacing were confirmed in all cases by device interrogation. Major arrhythmic events (MAE) were defined as sustained ventricular tachycardia or ventricular fibrillation, which were treated by the device with either shock or ATP. Twoblinded expert electrophysiologists confirmed the appropriateness of the device therapies.

Clinical parameters were used to state responders and non responders. Patients were assumed as responders if the following criteria met: (1) no cardiovascular death, (2) no hospitalization for decompensated HF and (3) >1-point decrease in NYHA functional class.

Statistical Analysis. Continuous variables are expressed as mean $\pm \mathrm{SD}$. Categorical variables, expressed as numbers or percentages, were analyzed using the Chi-square test or Fisher's exact test. Comparisons between normally distributed continuous variables were made using the Student $t$ test. The Mann-Whitney $U$ test was used for analysis of non-normally distributed data. The Cox proportional-hazards model was used to evaluate the risk of MAE in relation to $\triangle \mathrm{QTc}$, amiodarone usage and LVEDD. Variables showing significant group differences were entered into multivariate regression models. To evaluate interobserver and intraobserver variability, the Pearson correlation coefficient ( $\mathrm{r}$ ) was calculated for each ECG parameter. Statistical analyses were performed using Analyses were performed using the statistical package SPSS 16.0 software for Windows. A two-tailed $\mathrm{p}$ value of $<0.05$ was considered statistically significant.

\section{Results}

The characteristics of study population are given in Table 1. Mean age was $56.9 \pm 11.8$ years, $44(93.6 \%)$ of patients were male. Ischemic cardiomyopathy was present in $36(59.6 \%)$ patients. Mean ejection fraction of study population was $23.7 \pm 7.2 \%$ and mean QRS duration was 161.54 \pm 35.9 ms. Mean follow-up period was $16.0 \pm 7.1$ months. Thirty-one (66\%) patients were CRT-responders.

Comparison of electrocardiographic, echocardiographic measurements and NYHA Class of study population before and after CRT are given in Table 2. NYHA class significantly reduced after CRT implantation $(3.24 \pm 0.53$ vs $2.39 \pm 0.51$, $\mathrm{p}=0.001)$. EF increased without statistical significance $(23.7 \pm 7.0 \%$ vs $27.4 \pm 7.0 \%, p=0.07)$. Tpe interval $(104.1 \pm 20.4$ vs $122.03 \pm 33,0, p=0.02)$ and QTc dispersion $(84.66 \pm 37.7$ vs $100.36 \pm 59.8, \mathrm{p}=0.04)$ increased significantly after CRT implantation. Other electrocardiographic parameters did not change significantly after CRT implantation. 
Table 1

\section{Baseline characteristic of study population}

\begin{tabular}{|l|l|}
\hline Age (years) & $56.9 \pm 11.8$ \\
\hline Sex (Male) & $44(93.6 \%)$ \\
\hline Diabetes mellitus & $11(23.4 \%)$ \\
\hline Hypertension & $24(51.8 \%)$ \\
\hline Atrial fibrillation & $3(6 \%)$ \\
\hline Amiodarone usage & $24(51.1 \%)$ \\
\hline Ischemic cardiomyopathy (\%) & $36(59.6 \%)$ \\
\hline LAD (cm) & $4.8 \pm 0.6$ \\
\hline LVEDD (cm) & $7.2 \pm 0.7$ \\
\hline LVESD (cm) & $6.2 \pm 0.7$ \\
\hline EF (\%) & $23.4 \pm 6.2$ \\
\hline QRS duration (ms) & $161 \pm 35.6$ \\
\hline QT dispersion & $80 \pm 36.7$ \\
\hline QTC dispersion & $86.9 \pm 39.9$ \\
\hline NYHA class & $3.24 \pm 0.5$ \\
\hline Mean follow-up (months) & $16 \pm 7.1$ \\
\hline CRT responders & $31(66 \%)$ \\
\hline Arrhythmic event & $14(29 \%)$ \\
\hline
\end{tabular}

Abbreviations: LAD - left atrium diameter, LVEDD - left ventricular end-diastolic diameter, LVESD - left ventricular end-systolic diameter; EF - ejection fraction, NYHA - New York Heart Association.

Table 2

Electrocardiographic, echocardiographic measurements and NYHA Class; before and after CRT

\begin{tabular}{|l|l|l|l|}
\hline & Before CRT & After CRT & p value \\
\hline NYHA Class & $3.24 \pm 0.53$ & $2.39 \pm 0.51$ & 0.001 \\
\hline LA $(\mathrm{cm})$ & $4.93 \pm 0.65$ & $5.0 \pm 1.0$ & NS \\
\hline LVEDD $(\mathrm{cm})$ & $7.30 \pm 0.78$ & $6.20 \pm 0.69$ & NS \\
\hline LVESD $(\mathrm{cm})$ & $6.20 \pm 0.70$ & $6,0 \pm 0.98$ & NS \\
\hline EF $(\%)$ & $23.7 \pm 7.20$ & $27.40 \pm 7.10$ & 0.07 \\
\hline QRS duration $(\mathrm{ms})$ & $161.54 \pm 35.90$ & $151.44 \pm 40.4$ & NS \\
\hline QTd & $77.89 \pm 34.70$ & $86.32 \pm 50.80$ & NS \\
\hline Tpe duration $(\mathrm{ms})$ & $104.10 \pm 20.40$ & $122.03 \pm 33$ & 0.02 \\
\hline Tpe dispersion & $45.56 \pm 12.02$ & $54.44 \pm 34.43$ & NS \\
\hline QTc dispersion & $84.66 \pm 37.70$ & $100.36 \pm 47.40$ & 0.04 \\
\hline
\end{tabular}

Abbreviations: LAD - left atrium diameter, LVEDD - left ventricular end-diastolic diameter, LVESD - left ventricular end-systolic diameter; EF - ejection fraction, NYHA - New York Heart Association, QTc - corrected QT.

Study population divided into two groups according to presence of arrhythmic events (Table 3). 14 (29\%) patients received appropriate ATP or shock for arrhythmic events. Frequency of ischemic cardiomyopathy, DM, hypertension and arrhythmic event before CRT implantation were similar between groups. Age $(52.5 \pm 14.4$ vs $58.7 \pm 10.2, p=N S)$ and EF before CRT (20.40 \pm 3.4 vs $24.8 \pm 6.7, p=N S)$ were also similar between groups. Amiodarone use was more frequent (71.6\% vs $42.4 \%, \mathrm{p}=0.06$ ) and LVEDD before CRT $(7.56 \pm 0.66 \mathrm{~cm}$ vs $7.0 \pm 0.7 \mathrm{~cm}, \mathrm{p}=0.06)$ were higher in arrhythmic event group without statistical significance. As shown in Table 2 electrocardiographic measurements of repolarisation dispersion were also similar between groups. As given in Table 3, an additional analysis of groups intended to determine the change of repolarisation dispersion in groups; revealed a significant increase in QTd $(31.66 \pm 39.5$ vs $5.57 \pm 5.59, \mathrm{p}=0.03)$ and QTc dispersion $(40.19 \pm 46.6$ vs $4.39 \pm 14.35, \mathrm{p}=0.04)$ in arrhythmic event group.

Multivariate Cox proportional hazard analysis was performed, including $\Delta \mathrm{QTc}$ dispersion, amiodarone usage and LVEDD (Table 4). $\triangle$ QTc dispersion was the only independent predictor of arrhythmic event ( $\mathrm{p}=0.045$, CI 1.000-1.033).

\section{Discussion}

This study has shown that CRT is associated with an increase in Tpe duration and QTc dispersion in advanced heart failure patients. Another important finding is the increase in QTc dispersion predicts major arrhythmic events in CRT patients (Table 5).

Previous investigators have reported the role of repolarisation dispersion on the basis of ventricular malignant arrhythmias in heart failure patients [8-10]. Heterogenity of ventricular repolarisation facilitates transmural early after depolarization propagation and also can cause intramural conduction blocks that predispose to re-entrant tachyarrhythmias [11]. Measurement of QTd, JTd, and Tp-e interval from surface ECG provides an index of repolarisation dispersion [12, 13]. Our findings of increase in QTc dispersion and Tp-e interval after CRT are consistent with previous experimental and clinical studies [14, 15]. Fish et al. [14] observed that reversing the direction of LV wall activation leads to an increase in QTc duration in arterially perfused canine LV wedge preparations. This has been linked to increased transmural dispersion of repolarisation resulting from earlier repolarisation of the epicardium and delayed activation and repolarisation of the midmyocardial M cells. In a clinical study Santangelo et al. [16] studied 50 CRT patients with end-stage heart failure and showed that left ventricular epicardial only pacing increase QTd, JTd and Tp-e interval whereas biventricular pacing reduced these parameters.

Following mentioned above studies; clinical studies focused on predicting arrhythmic events by using same ECG parameters in CRT patients. Chalil et al. [17] examined retrospectively the prognostic value of these parameters in predicting sudden cardiac death in CRT patients. Like our study they reported that increase in QT dispersion was the independent predictor of sudden cardiac death. In their study primary end point was sudden cardiac death but sudden cardiac death is not always due to ventricular arrhythmias. In our study all patients received CRT-D devices so we could catch all sustained ventricular arrhythmias during follow-up period. Lellouche $\mathrm{N}$ et al. [18] investigated the same ECG parameters in CRT patients. They reported that Tp-e interval increased after CRT implantation in patients with LBBB or narrow QRS at baseline. Another important finding was the post implantation Tp-e interval was the independent predictor of ICD therapy. Although our study has similarities with Lellouche's study there are main differences especially in study group; our study group consisted of patients with QRS duration >120 ms whereas Lellousche's groups consisted of 
Table 3

Electrocardiographic measurements and clinical characteristics of patients with and without arrhythmia

\begin{tabular}{|c|c|c|c|}
\hline & Patients with arrhythmia $(n=14)$ & Patients without arrhythmia $(n=34)$ & $P$ value \\
\hline Ischemic cardiomyopathy & $\% 35.7$ & $\% 42.4$ & NS \\
\hline Diabetes mellitus & $\% 7.1$ & $\% 30.3$ & NS \\
\hline Amiodarone usage & $\% 71.6$ & $\% 42.4$ & NS $(0.06)$ \\
\hline Age (years) & $52.5 \pm 14.4$ & $58.7 \pm 10.2$ & NS \\
\hline LVEDD (Before CRT) (cm) & $7.56 \pm 0.66$ & $7 \pm 0.7$ & NS (0.06) \\
\hline EF (Before CRT) (\%) & $20.40 \pm 3.4$ & $24.8 \pm 6.7$ & NS \\
\hline LVEDD (After CRT) (cm) & $7.10 \pm 0.8$ & $7.10 \pm 0.9$ & NS \\
\hline EF (After CRT) (\%) & $27.90 \pm 6.4$ & $25.6 \pm 8.1$ & NS \\
\hline QRS duration before CRT (ms) & $172.31 \pm 32.18$ & $155.56 \pm 36.51$ & NS \\
\hline QRS duration after CRT (ms) & $156.41 \pm 25.64$ & $149.32 \pm 22.13$ & NS \\
\hline QTd (Before CRT) & $70 \pm 20.28$ & $84.44 \pm 40.12$ & NS \\
\hline Tpe (Before CRT) & $114 \pm 27.49$ & $102.15 \pm 18.86$ & NS \\
\hline QTc dispersion (Before CRT) & $76.08 \pm 28.57$ & $91.78 \pm 43.61$ & NS \\
\hline QTd (After CRT) & $93.85 \pm 46.46$ & $78.52 \pm 39.19$ & NS \\
\hline Tpe (After CRT) & $124.36 \pm 33.52$ & $120.4 \pm 33.52$ & NS \\
\hline Tpe dispersion (After CRT) & $59.17 \pm 44.81$ & $50 \pm 27.87$ & NS \\
\hline QTc dispersion (After CRT) & $109.12 \pm 54.02$ & $91.3 \pm 45.57$ & NS \\
\hline
\end{tabular}

Table 4

Change of repolarization dispersion parameters in patients with and without arrhythmia

\begin{tabular}{|l|l|l|l|}
\hline & Patients with arrhythmia $(n=14)$ & Patients without arrhythmia $(n=34)$ & P value \\
\hline$\Delta$ QTd & $31.66 \pm 39.5$ & $5.57 \pm 5.59$ & 0.03 \\
\hline$\Delta$ Tpe & $14.82 \pm 34.95$ & $19.35 \pm 33.96$ & NS \\
\hline$\Delta$ Tpe dispersion & $10 \pm 6.44$ & $0.35 \pm 4.67$ & NS \\
\hline$\Delta$ QTc dispersion & $40.19 \pm 46.6$ & $4.39 \pm 14.35$ & 0.04 \\
\hline
\end{tabular}

three different patient groups; with narrow QRS complex, LBBB and upgraded right ventricular paced patients. So our study can represent general CRT patient population.

Ermis et al. reported that arrhythmia frequency and number of appropriate ICD treatments were reduced after upgrade to CRT-ICD for HF treatment [19]. The CAREHF study [20] has demonstrated that CRT reduced sudden cardiac death in heart failure patients in 2 years follow-up.

Randomized controlled studies on the safety and efficacy of cardiac resynchronization suggest that this therapy may have a neutral or antiarrhythmic effect. However, a potentially proarrhythmic effect has been described, and while relatively infrequent, clinicians should be aware of this phenomena. The ultimate impact on arrhythmic vulnerability is likely dependent on propagation patterns and the underlying cardiac substrate. As demonstrated by this study and several studies mentioned here, reversal of transmural activation and repolarisation may set the stage for re-entry and proarrhythmia.

Our results demonstrated important findings: firstly; repolarisation dispersion in means of QTc dispersion and mean Tpe duration increased following CRT implantation; secondly, increase in QTc dispersion predicts major antiarrhythmic events in CRT patients.
Table 5

\section{Predictors of arrhytmic event}

\begin{tabular}{|l|l|l|}
\hline & $p$ value & Confidence Interval \\
\hline QTc dispersion & 0.045 & $1.000-1.033$ \\
\hline LVEDD & 0.99 & \\
\hline Amiodarone usage & 0.15 & \\
\hline
\end{tabular}

\section{Conclusion}

Our study has shown that CRT causes a significant increase in QTc dispersion and Tpe interval in advanced heart failure patients also increase in QTc dispersion predicts one-year MAE in this population.

\section{Study limitations}

This study has several limitations. First, it is small and observational single centre study. Second, the electrocardiographic measurements were performed manually on paper-printed ECG may limit the accuracy and reproducibility of the measurements. Third, the surface ECG has limitations reflecting the cardiac electric activity compared to body surface mapping or vector cardiography. 


\section{References}

1. Cleland J, Daubert JC, Erdmann E, et al. Cardiac Resynchronization-Heart Failure (CAREHF) Study Investigators. The effect of cardiac resynchronization on morbidity and mortality in heart failure. N Engl J Med 2005;352: 1539-49.

2. Lindenfeld J, Feldman AM, Saxon L, et al. Effects of cardiac resynchronization therapy with or without a defibrillator on survival and hospitalizations in patients with New York Heart Association class IV heart failure. Circulation. 2007;115: 204-12.

3. Prinzen FW, Vernooy K, De Boeck BWL, et al. Mechano-energetics of the asynchronous and resynchronized heart. Heart Fail Rev. 2011;16: 215-24.

4. Ukkonen $\mathrm{H}$, Sundell J, Knuuti J. Effects of CRT on myocardial innervation, perfusion and metabolism. Europace. 2008;10 Suppl 3: iii114-7.

5. Bristow MR, Saxon LA, Boehmer J, et al. Comparison of Medical Therapy, Pacing and Defibrillation in heart failure (COMPANION) Investigators. Cardiac-resynchronization therapy with or without an implantable defibrillator in advanced chronic heart failure. $\mathrm{N}$ Engl J Med 2004;350: 2140-50.

6. Carson P, Anand I, O'Connor C, et al. The comparison of Medical Therapy, Pacing and Defibrillation in heart failure (COMPANION) Trial. J Am Coll Cardiol 2005;46: 2329-34.

7. Fish JM, Di Diego JM, Nesterenko V, et al. Epicardial activation of left ventricular wall prolongs QT interval and transmural dispersion of repolarization. Circulation 2004;109: 2136-42.

8. Erikssen G, Liest I K, Gullestad L, et al. The terminal part of the QT interval (T peak to $T$ end): a predictor of mortality after acute myocardial infarction. Ann Noninvasive Electrocardiol. 2012 Apr; 17 (2): 85-94.

9. Vaseghi M, Lux RL, Mahajan A, et al. Sympathetic stimulation increases dispersion of repolarization in humans with myocardial infarction. Am J Physiol Heart Circ Physiol. 2012 May 1;302 (9): H1838-46.

10. Xu T, Wang $\mathrm{H}$, Zhang $\mathrm{J}$, et al. Effects of mid-myocardial pacing on transmural dispersion of repolarization and arrhythmogenesis. Europace. 2012 Sep;14 (9): 1363-8.
11. Bernus $\mathrm{O}$, Zemlin $\mathrm{CW}$, Zaritsky RM, et al. Alternating conduction in the ischaemic border zone as precursor of reentrant arrhythmias: a simulation study. Europace. 2005 Sep;7 Suppl 2: 93-104.

12. Antzelevitch $\mathrm{C}$. Role of transmural dispersion of repolarization in the genesis of druginduced torsades de pointes. Heart Rhythm 2005;2:9-15.

13. Opthof T, Coronel R, Wilms-Schopman FJG, et al. Dispersion of repolarization in canine ventricle and the electrocardiographic $T$ wave. The $T p-e$ interval does not reflect transmural dispersion. Heart Rhythm 2007;4: 341-8.

14. Fish JM, Di Diego JM, Nesterenko V, et al. Epicardial activation of left ventricular wall prolongs QT interval and transmural dispersion of repolarization. Circulation 2004;109: 2136-42.

15. Fish JM, Brugada J, Antzelevitch C. Potential proarrhythmic effects of biventricular pacing. J Am Coll Cardiol 2005;46: 2340-7.

16. Santangelo $\mathrm{L}$, Ammendola $\mathrm{E}$, Russo $\mathrm{V}$, et al. Influence of biventricular pacing on myocardial dispersion of repolarization in dilated cardiomyopathy patients. Europace. $2006 \mathrm{Jul} ; 8$ (7): 502-5.

17. Chalil S, Yousef ZR, Muyhaldeen SA, et al. Pacing-Induced increase in QT dispersion predicts sudden cardiac death following cardiac resynchronization therapy. J Am Coll Cardiol 2006;47: 2486-92.

18. Lellouche N, De Diego C, Akopyan G, et al. Changes and predictive value of dispersion of repolarization parameters for appropriate therapy in patients with biventricular implantable cardioverter-defibrillators. Heart Rhythm. 2007 Oct;4 (10): 1274-83.

19. Ermis $C$, Seutter R, Zhu AX, et al. Impact of upgrade to cardiac resynchronization therapy on ventricular arrhythmia frequency in patients with implantable cardioverter-defibrillators. J Am Coll Cardiol. 2005 Dec 20;46 (12): 2258-63.

20. Cleland JGF, Daubert JC, Erdmann E, et al. on behalf of the CARE-HF Study Investigators. Longer-term effects of cardiac resynchronization therapy on mortality in heart failure [the Cardiac Resynchronization-Heart Failure (CARE-HF) trial extensive phase]. Eur Heart $\mathrm{J}$ 2006;27: 1928-32. 